\title{
A PRÁTICA DA CITAÇÃO NA UNIVERSIDADE* AS REFERÊNCIAS À INFORMAÇÃO CIENTÍFICA EM TRABALHOS ACADÊMICOS
}

\author{
QUOTATION PRACTICES IN UNIVERSITY ENVIRONMENTS \\ REFERENCES TO ACADEMIC INFORMATION IN ACADEMIC \\ RESEARCH
}

\section{Cosme Batista dos Santos ${ }^{\star \star}$}

Aquele que apreende a enunciação de outrem não é um ser mudo, privado da palavra, mas ao contrário, um ser cheio de palavras interiores.

Mikhail Bakhtin, 2006, p.147.

\section{RESUMO}

Os estudos sobre a citação como objeto do letramento acadêmico ou universitário ainda são raros na linguística aplicada brasileira; no entanto, a prática da citação é um objeto privilegiado para compreendermos a complexidade do acesso às referências teóricas e à escrita de pesquisa na Universidade. Este trabalho tem como pressupostos centrais o letramento informacional, em sua abordagem inclusiva (SILVA, 2008), e o letramento ecológico, em sua abordagem sociodiscursiva (BARTON, 1998; IVANIC, 1998; KLEIMAN, 1995). A partir desse pressuposto, portanto, o evento de letramento mediado pela escrita de pesquisa e pelo uso da citação na universidade deve ser percebido como uma prática discursiva (COMPAGNON, 1996; BOCH \& GROSSMANN, 2001 e 2002) e, nessa perspectiva, a investigação sobre os modos de referência ao discurso teórico, incluindo a citação de fontes, permite trazer à tona os problemas de acesso à informação e ao discurso teórico e, ao mesmo tempo, de acesso ao letramento universitário em diferentes países e contextos socioculturais. A pesquisa analisou 30 (trinta) trabalhos acadêmicos de final de curso de duas universidades brasileiras - a Universidade do Estado da Bahia (UNEB) e a Universidade Estadual de Campinas (UNICAMP) - e de uma universidade portuguesa, a Universidade do Porto (UP). No total de trabalhos pesquisados, identificamos 699 (seiscentos e noventa e nove) referências ao discurso teórico, incluindo a citação, sendo 249 nos trabalhos dos

\footnotetext{
* Este trabalho é resultado de uma pesquisa de pós-doutoramento realizada na Faculdade de Letras da Universidade do Porto (FLUP), Portugal, sob a supervisão do Dr. Armando Malheiro da Silva e com o apoio da Universidade do Estado da Bahia (UNEB). Agradeço à Coordenação de Aperfeiçoamento de Pessoal de Nível Superior - CAPES pelo apoio que tornou possível o Estágio. ** Universidade do Estado da Bahia, Salvador, Bahia, Brasil.cosmebs.santos@gmail.com
} 
estudantes da UNEB, 195 nos trabalhos dos estudantes da UNICAMP e 255 nos trabalhos dos estudantes da UP. Após a análise qualitativa dos dados, constatamos que, tal como apontam os pesquisadores franceses Françoise Boch e Francis Grossmann, estudantes de ambos os países utilizam com mais frequência o recurso da citação autônoma, ou seja, a inserção literal de partes do discurso teórico de referência enquanto as reformulações e evocações são menos valorizadas no conjunto dos trabalhos. Os dados sugerem, portanto, que essa tendência se deve mais ao estágio de iniciação à escrita de pesquisa do que a fatores ligados aos contextos socioculturais ou de nacionalidade.

Palavras-chave: Letramento; escrita de pesquisa; citação; identidade enunciativa.

\section{ABSTRACT}

Studies on quotation as object of academic or university literacy are still rare in the field of applied linguistics in Brazil. However, quotation practices are a privileged object of study to help us understand the complexity of access to theoretical references and to research writing at university levels. This work adopts as central assumptions information literacy in its inclusive approach (SILVA, 2008) and ecological literacy in its sociodiscursive approach (BARTON, 1998; IVANIC, 1998; KLEIMAN, 1995). Based on such assumptions, the literacy event mediated by research writing and by the use of quotation in university environments should be seen as a discursive practice (COMPAGNON, 1996; BOCH \& GROSSMANN, 2001 and 2002). From this perspective, the research on modes of referencing, including source quotation, allows to shed light into problems regarding access to information and to theoretical discourse, as well as access to university literacy in different countries and sociocultural contexts. This work analyzed thirty (30) academic end-of-course papers from two Brazilian universities - the State University of Bahia (UNEB) and the State University of Campinas (Unicamp) - and from one Portuguese university - the University of Porto (UP). Out of the total papers analyzed, we identified six hundred ninety-nine (699) references to theoretical discourse, including quotations; of that total, 249 belonged to UNEB students, 195 to Unicamp students and 255 to UP students. After the quantitative analysis we noticed that - just as observed by French researchers Françoise Boch and Francis Grossmann- students from both countries tend to use more often autonomous quotations, that is, the literal insertion of parts of theoretical discourse references, rather than reformulations and evocations. Data suggest that such trend appears to be linked to the fact that students are at initial stages of research writing practices and not to sociocultural context or nationality related factors.

Keywords: Literacy, research writing, quotation, enunciation identity.

\section{INTRODUÇÃO}

Na universidade, a escrita da pesquisa é a prática de letramento de que os alunos participam com mais frequência. Durante a experiência universitária, os estudantes,

1 Nas Universidades Portuguesas, o Trabalho de Conclusão de Curso (TCC) recebe o nome de Trabalho de Final de Curso (TFC). Nas realidades brasileira e portuguesa, esse trabalho é uma exigência dos cursos de licenciaturas e bacharelados como requisito para obtenção do titulo de graduado e pode ser apresentado sob a forma de monografia. Neste estudo, as nomenclaturas TFC ou TCC englobam todos os trabalhos de final de curso, independentemente do gênero: relatórios de estágio, monografias, dissertação, etc. 
independentemente de sua origem social e cultural, são desafiados ao aprendizado dos gêneros acadêmicos escritos e, por isso, fazem leituras de artigos científicos, escrevem resenhas e, principalmente, escrevem trabalhos de conclusão ou de final de curso (TCC) ${ }^{1}$, sob a forma de monografia ou relatório de estágio. Nas monografias, um dos desafios mais marcantes é a citação da informação científica, tendo em vista a inserção de referências teóricas nos pressupostos da pesquisa. $\mathrm{O}$ mapeamento das práticas de citação em trabalhos acadêmicos e nas monografias de estudantes universitários é objeto sedutor e pode nos ajudar a revelar, inicialmente, a diversidade dos modos de referência à informação científica e teórica, mas, além disso, pode apontar indícios de como esses estudantes se relacionam com as fontes teóricas ou de como constroem a identidade enunciativa (GUIBERT, 2001) com os textos teóricos de referência, tendo em vista o aprendizado da escrita de pesquisa. As práticas de citação podem, sem dúvida, trazer amplos conhecimentos sobre a construção da identidade enunciativa entre o autor e as suas fontes e, além disso, fornecer importantes informações sobre condição de leitura e de escrita nas universidades e, ainda, apontar caminhos para a elaboração de políticas de inclusão de jovens e de grupos de diferentes contextos culturais nas práticas de letramento proporcionadas pela Universidade.

Dessa forma, a pesquisa aqui proposta terá uma dupla relevância. Em primeiro lugar, uma relevância teórica, uma a vez que há, nos contextos brasileiro e português, poucos estudos sobre a citação na perspectiva da linguística aplicada e da ciência da informação aplicada, além de o próprio tema da Citação ainda não ser investigado como um objeto de estudos do letramento ou do letramento informacional, de forma que a prática social e cultural da citação acadêmica, longe do controle das normas técnicas, é um fenômeno textual-discursivo muito importante nas práticas de escrita acadêmica e ainda pode nos dizer muito sobre o letramento na universidade. Em segundo lugar, uma relevância social, uma vez que os resultados dessa pesquisa deverão mostrar, não só a diversidade das práticas de referência teórica na Universidade e as fragilidades de certas metodologias de ensino das teorias, mas também apontar alternativas de acompanhamento, via observatório, da trajetória dos jovens na educação superior no Brasil e em Portugal. As universidades parceiras, ao incentivarem esta pesquisa, podem tornar evidentes os problemas implicados na aquisição da escrita de pesquisa pelos estudantes na iniciação científica, mas, além disso, podem tomá-los como ponto de partida para a promoção de fóruns, seminários sobre metodologias de ensino do conhecimento teórico e sobre a inclusão social da juventude na educação superior. Enfim, o objetivo da pesquisa é, então, investigar as práticas de citação da referência teórica, apontando os problemas de uso da referência, mas também as hipóteses que esses 
problemas podem apontar, tendo em vista a aquisição da citação na escrita de pesquisa e do letramento na Universidade.

A pesquisa em sua totalidade envolve um corpus contendo as práticas de citação de estudantes de licenciaturas de universidades brasileiras, a saber, Universidade do Estado da Bahia (UNEB) e Universidade Estadual de Campinas (UNICAMP), e de uma universidade portuguesa, a Faculdade de Letras da Universidade do Porto (FLUP). As questões da pesquisa para este estudo são: como os estudantes fazem referências teóricas ao discurso do outro em trabalhos acadêmicos? Que tipos ou modalidades de referências são preferencialmente utilizados por estudantes brasileiros e portugueses? $\mathrm{O}$ que os diferentes modos de referência ao discurso do outro (BOCH \& GROSSMANN, 2002) revelam sobre o nível ou grau de identidade enunciativa (GUIBERT, 2001) com as fontes teóricas? As respostas para essas questões podem apontar que: (i) apesar da presença dos documentos de normatização, as práticas de citação são variadas; (ii) as diferenças de modos de citar revelam também uma diversidade de modos de posicionamentos e de identidade enunciativa com as informações teóricas; (iii) a identidade enunciativa implica melhor gerenciamento das informações teóricas na escrita e (iv) a identidade enunciativa e o gerenciamento de vozes são consequências das "boas" práticas de leitura de referenciais e das competências conceitual e teórica, ou seja, sem $\mathrm{o}$ acesso às informações e sem leituras, os estudantes tendem a copiar partes da obra de referência e, por isso, são mal sucedidos no "enxerto" dos conceitos e das informações teóricas em sua escrita de pesquisa.

\section{PRESSUPOSTOS TEÓRICOS}

\subsection{Letramento: a ecologia da informação na escrita de pesquisa}

Os pressupostos fundamentais para a investigação resultam de uma construção interdisciplinar, tal como pressupõe a maior parte das pesquisas em linguística aplicada e em ciência da informação aplicada que se concentram em investigações sobre o letramento, incluindo as práticas da escrita de pesquisa e, particularmente, a citação de informações e conceitos científicos. Nessa perspectiva, a investigação proposta se baseou no pressuposto de que o letramento é uma prática social 'ecologicamente' configurada (BARTON, 1994; KLEIMAN, 1995) em que o evento de leitura e escrita é parte de uma prática social, de uma ecologia textual-discursiva, em que os bibliotecários, os formadores e as condições físicas, etc. disponibilizam acervos, 
informações e discursos aos estudantes para apoiar suas práticas de produção de gêneros acadêmicos variados. Partindo desse pressuposto, já bastante enfatizado nas pesquisas sobre as práticas sociais da escrita, a nossa hipótese é a de que as práticas citantes são diretamente apoiadas nas competências leitoras e, como tais, diretamente integradas ao controle e gerenciamento das relações intertextuais na passagem de informações, conceitos e posicionamentos de um texto escrito dito científico ou teórico para a escrita de pesquisa em formação.

Ivanic (1998), citando Barton (1994), acrescenta que a metáfora da 'ecologia do letramento' ${ }^{2}$ transmite a idéia de que um variado número de fatores sociais inter-relacionados apoia a sobrevivência de determinados atos de leitura e escrita, assim como, por exemplo, um variado número de fatores físicos ambientais interrelacionados suporta a sobrevivência de uma espécie particular de réptil ou de anfíbio. Como sugerem os autores, todos os atos de leitura e escrita têm seu próprio «nicho ecológico», e esses ajustes culturais são extermemante diversificados e instigantes.

No Brasil, as universidades assumem os desafios de ampliação de suas vagas para jovens de diferentes condições social e cultural. Por outro lado, no ensino médio brasileiro, em especial na rede pública de ensino, esses estudantes têm pouco acesso à escrita de pesquisa ou aos modos de dizer e de escrever privilegiados na universidade. As universidades, por sua vez, cobram dos estudantes de primeiro período ou semestre, por exemplo, a leitura de artigos científicos, muitas vezes sem uma mediação que possibilite melhor familiarização com esses textos e a apropriação da informação pelos estudantes. Além disso, há uma cisão muito peculiar entre o trabalho do bibliotecário, que se resume em organizar e disponibilizar o acervo, e o trabalho do professor, que indica a obra, expõe conceitos e resultados e cobra as citações aos estudantes.

A perspectiva ecológica, a nosso ver, sendo bem entendida no contexto do letramento acadêmico, pode ajudar a diminuir essa distância entre o estudante e todos os agentes da instituição que estão encarregados de mediar o acesso à escrita. Inicialmente, é importante deixar claro que o letramento acadêmico não é uma prática de escrita descontextualizada. A escrita de pesquisa é tendencialmente produzida e lida em contextos não imediatos ou desprovidos da interação face-aface, tal como é mais comum na linguagem falada em geral, mas isso não signifca, a

2 "The metaphor of the ecology of literacy also conveys the idea that a large number of interrelated social factors support the survival of particular acts of reading and writing, just as, for example, a large number of interrelated physical factors support the survival of a particular species of newt acts de reading and writing all have their own 'ecological niche' and these cultural settings are extremely diverse" (IVANIC, 1998). 
rigor, pressupor que a escrita e as práticas de letramento sejam descontextualizadas ou desprovida dessa dependência dos fatores sociais e das mediações de inúmeros agentes para que a sua configuração final proceda e a aprendizagem seja eficaz.

A ideia de que os letramentos são descontextulizados é coerente apenas com uma visão extremamente simplista do contexto, ou seja, vale apenas quando o contexto é concebido estritamente em termos de ambiente físico e da presença física das pessoas. Nesse caso, sim, há uma diferença importante entre a comunicação face-a-face, mais comum na lingua fala, e a comunicação a distância, mais comum na lingua escrita. Evidentemente, a maioria das práticas de lingua falada ocorre com a presença física dos interlocutores, enquanto a maioria das práticas de linguagem escrita ocorre sem a presença física dos interlocutores, ou seja, "os interlocutores da escrita são separados no espaço e no tempo e não compartilham o mesmo ambiente físico" (IVANIC, 1998, p. 62). Um bom exemplo é a escrita acadêmica que difere em muitos aspectos da escrita produzida em contextos mais familiares, como é o caso de bilhetes, cartas pessoais, e-mails, etc. Na prática de escrita acadêmica, o estudante está trabalhando em seu quarto, cercado de livros, revistas, manuais, notas de aula e, talvez, de transcrições de entrevistas. Nesse contexto de leitura e de acesso à informação por meio da escrita, embora haja interlocução, ela ocorre a distância, porque é através da escrita que o leitor acessa conceitos, informações, as posições dos autores, e constroem sua identidade enunciativa com os posicionamentos teóricos e conceituais dos autores lidos.

O letramento informacional (ou a literacia informacional), nesse caso, pode nos ajudar a explicar melhor essa complexidade, já que eliminando a apropriação dos suportes da escrita - a exemplo dos gêneros discursivos artigos, monografias, resenhas, etc. -, o objeto de excelência da pesquisa torna-se a referência aos conceitos ou a posições científicas no quadro teórico de monografias e relatórios de estágio. Nesse sentido, sendo o objeto de citação uma informação ou conceito teórico, o conceito de letramento informacional é, a nosso ver, o que torna opaca a prática de letramento da universidade, que se configura por meio da utilização de referência teórica em escrita de pesquisa. Como aponta Armando Silva (2006),

O letramento informacional são as competências e a capacidade seletiva e sintetizadora na busca e uso da informação. Este tipo de letramento relaciona-se estreitamente com o geral, mas pode ser posto em destaque como uma espécie de introdução geral e interdisciplinar aos estudos comportamentais em torno da informação. Determinar o tipo de competências aprendidas, assim como as necessidades espontâneas ou induzidas ao longo do processo de escolarização no que toca a buscar, reproduzir/citar, interiorizar e comunicar informação. (SILVA, 2006: p. 154). 
Nas práticas da escrita de pesquisa, portanto, quando se trata do foco na citação, não há dúvida de que o gerenciamento de informações ou conceitos na escrita não pode ser investigado sob o pressuposto de conceitos guarda-chuvas como letramento científico ou letramento acadêmico. Nesses casos, particularmente, a pesquisa foca interesses bem mais amplos que incluem as competências ligadas ao próprio fazer científico e ao conjunto dos gêneros e suportes acadêmicos. Neste trabalho, o foco central é a retextualização (ou intertextualização) dos conceitos teóricos, portanto, fala-se de competências implicadas na busca adequada dos conceitos nas obras teóricas de referência e na inserção ou no enxerto desses conceitos em trabalhos acadêmicos, visando às demandas de interação: com os pares, quando se trata de uma comunicação científica em revistas especializadas; com o grande público, quando se trata de divulgação científica; e com os examinadores, quando se trata de trabalhos acadêmicos de estudantes em final de curso. A relação entre o letramento informacional, na formulação de Silva (2006), e o letramento social, na formulação de Barton (1994), refere-se a esse foco na competência de gerenciar, de intertextualizar, uma informação de um texto fonte em outro texto destino, tendo em vista os diferentes contextos receptivos, cada um com a sua orientação social que, inevitavelmente, implica estados distintos de uso da referência, da citação e de aprendizado da escrita de pesquisa.

A denominação letramento social é um deslocamento de uma abordagem universal, para uma abordagem que leva em conta as práticas sociais específicas como as práticas acadêmicas de uso da escrita e da informação. Assim sendo, a formulação letramento informacional, embora desloque o conceito para um ponto da escrita, não pode correr o risco de ignorar a especificidade dos gêneros acadêmicos ou do comportamento enunciativo da informação quando é enunciada no artigo científico, por exemplo. Nesse caso, propomos que a visão social e ecológica do letramento seja integrada ao letramento informacional, sob a denominação letramento acadêmico informacional ou letramento informacional da esfera discursiva acadêmica on universitária. Desse modo, fica assegurada a dimensão social e ecológica - os estudantes acessam os gêneros do discurso teórico em uma enunciação acadêmica particular - e, ao mesmo tempo, a dimensão informacional - os estudantes acessam, no interior desses gêneros, uma informação teórica, através da citação, por exemplo.

\subsection{0 estado da citação na Universidade}

O estado da citação é o quadro da revisão bibliográfica que fundamenta a proposta de trabalho com a citação acadêmica enquanto prática discursiva. Para 
desenvolver esse quadro, trouxemos dois tópicos, a saber, o papel da leitura na citação e a prática da citação na universidade.

\subsubsection{0 papel da leitura na citação}

A hipótese inicial do nosso estudo é a relevância da leitura, aliás, de um bom exercício de leitura, como pressuposto da construção de "identidades enunciativas bem sucedidas" (GUIBERT, 2001), indispensáveis às "boas" práticas de citações. A leitura, no sentido aqui apontado por Antoine Compagnon, é configurada por uma relação de "acomodação", "solicitação" e da "leitura em ação" com os textos dos quais extrai as informações a serem citadas. Não é o texto uma prateleira disponibilizando mercadorias, como lembra bem Marcuschi (2001), em seu vasto estudo sobre a retextualização. O texto ou enunciado é parte inseparável da enunciação e como tal é dinamizado pela relação intersubjetiva de autor e leitor que interagem com propósitos definidos em cada ato singular de leitura.

No livro, O trabalbo da citação, particularmente nos capítulos intitulados "Acomodação" e "Solicitação", Compagnon (1996) nos ajuda a formatar um pressuposto central desta investigação que é a citação como uma atividade enunciativa ou como um jogo de posições. A acomodação e a solicitação, a nosso ver, são as primeiras imagens da leitura que sinalizam a identidade enunciativa do leitor com o texto, com a fonte de informação, porém, no que tange particularmente à "acomodação", ainda é o texto que deve oferecê-la ao leitor para não abortar o seu interesse pela leitura. No contato com a fonte de citação, o leitor deve se acomodar ao texto e encontrar nele o lugar permitido, legibilidade e aceitabilidade. Em outros termos, os livros devem oferecer aos seus leitores condições de leitura compatíveis com as demandas e com os hábitos dos leitores, mas é o leitor específico que se acomoda ao texto, que percebe esse lugar a priori oferecido e permitido pelos livros. Quando um texto não oferece acomodação para o leitor e o leitor não se acomoda a ele, tem-se uma leitura inacessível e, portanto, incompatível com as demandas de citação. Finalmente, para confirmar a nossa hipótese de que a busca de informação teórica é também uma interação com os textos, é preciso pressupor já de agora que a citação é um elemento privilegiado da acomodação, pois ela é um lugar de reconhecimento, uma marca de leitura. É, sem dúvida, "a razão pela qual nenhum texto, por mais subversivo que seja, renuncia a uma forma de citação" (COMPAGNON, 1996, p.22).

Como parte desse processo interativo entre o leitor e o texto teórico, a solicitação é a comoção absoluta do leitor diante do texto e de pontos do texto 
que lhe fixam. É um encantamento, a excitação que intervém após a acomodação. Segundo o autor, quando a excitação intervém, ela busca no texto o alicerce da informação, as raízes da solicitação; no entanto, a excitação nunca remonta à origem, jamais reencontra o abalo inicial ou original e intratável (COMPAGNON, 1996). O leitor pode ficar excitado diante de um artigo e diante e certos conceitos que ele divulga, podendo grifá-los, recortá-los, rasgá-los e cobri-los de injúrias, porém não consegue alcançar o abalo inicial. O abalo original é inacessível, porque está, ao mesmo tempo, dentro do texto e fora dele, na configuração imaginária da leitura, da qual o leitor, com todo o seu corpo, é parte recebedora e o último referente.

Nesses termos, a solicitação é para a leitura como uma figura introdutória: sem ela, não há leitura, e, se ainda há, não se pode dizer que há prazer ou fruição. A solicitação é o ponto da excitação com a leitura, nenhum leitor busca informação em um texto, sem contar com essa possibilidade de encantamento com o discurso dos textos, incluindo os discursos teóricos. É preciso perguntar se um leitorinvestigador, por exemplo, que não persegue esse encantamento, é de fato um leitorinvestigador e se, não sendo, é possível construir identidade enunciativa, conhecer os aspectos infratextuais e intertextuais e fazer o transplante de conteúdos para suas escritas.

A leitura, no sentido aqui mencionado, é a garantia de uma viagem bem sucedida, rumo à informação a ser intertextualizada no texto que a espera para atingir o seu estado de unidade, aliás, de uma nova fonte de informação. Sem a "solicitação", há uma leitura dos significados, mas não ainda do encantamento, da excitação. A configuração proposta pelo autor, a nosso ver, não é restrita ao ato de ler na literatura, apesar de haver uma crença de que o prazer da leitura é tributário da leitura literária. Em nossa investigação, nós vamos direcionar essa perspectiva de leitura para qualquer leitura, incluindo a leitura da escrita da pesquisa, cuja finalidade é construir uma identidade discursiva bem sucedida entre o leitor e suas fontes de informações, tendo em vista a capacidade de realizar operações de citações, menos aleatórias ou sem costuras nas práticas de escrita de pesquisa na Universidade. A propósito dessa preocupação, Guibert (2001) esclarece que,

Um dos objetivos em formação será mostrar como o autor pode se engajar no seu texto correndo o risco de errar, porém assinalando bem o início do seu trabalho de interpretação. Um objetivo complementar será fazer exibir a "cozinha" que permitiu constituir a informação, tanto o intertexto quanto o intertexto. (GUIBERT, 2001, p. 42)

3 "Un des objectifs en formation sera de montrer comment l' auteur peut s'engager dans son texte au risque de se tromper, mais en marquant bien le début de son travail d'interpretation. Un objectif complémentaire sera de faire exbiber la "cuisine" qui a permis de constituer l'information, tant l'intertexte que l'infratexte." 
$\mathrm{Na}$ formação universitária, portanto, o ensino da escrita de pesquisa precisa ser apoiado pela leitura e interpretação das fontes de informação. O trabalho de interpretação deve exibir o processo que permitiu constituir a informação, tanto no que concerne ao gerenciamento dos intertextos - relações que o texto teórico, por exemplo, estabelece com outros textos também teóricos - quanto em relação ao aprofundamento no infratexto, ou seja, na relação que o texto teórico estabelece com seu contexto ou com sua condição social de produção.

\subsubsection{As práticas de citação na Universidade}

Os estudos sobre a citação no contexto das pesquisas em linguística aplicada e na ciência da informação ainda são poucos. Para este breve estado da arte, portanto, optamos por trazer, mais especificamente, um quadro das pesquisas sobre os modos de referência ao discurso do outro na escrita de pesquisa, tendo em vista o mapeamento dos modos de citação científica por especialistas e por estudantes de universidade (BOCH \& GROSSMANN, 2001; 2002). Os trabalhos desses pesquisadores, por exemplo, estudam a relação entre a prática da citação realizada por estudantes em seus trabalhos acadêmicos, relatórios de pesquisa e de final de curso e a condição social de leitura; ao mesmo tempo, produz reflexões e direcionamentos para a política de letramento, tendo em vista melhoria da condição social da leitura e de acesso ao letramento nas Universidades.

Os estudos se apoiam no pressuposto da enunciação e na visão dialógica da escrita (BAKHTIN, 2006; MARCUSCHI, 2001), ou seja, em uma visão que permite considerar a citação um trabalho, uma atividade entre os sujeitos em uma enunciação específica, por exemplo, na produção de gêneros acadêmicos (MATÊNCIO, 2003). Em outros termos, a citação é mais do que a inserção mecânica, sobreposta, de uma informação ou de conceitos na tessitura de um texto relatório de pesquisa, por exemplo. A citação é um jogo de posições, um processo de ancoragem enunciativa que requer, previamente, exame de compatibilidade intertextual (COMPAGNON, 2007) entre o texto acadêmico produzido pelo estudante e os textos de referência teórica em jogo. As relações entre os textos são, também, marcadas pelas relações interculturais, e relações de poder nem sempre explicitas na cultura universitária, ou seja, entre as condições de leitura e de acesso à informação teórica e as práticas de citações, padrões estéticos e posicionamentos diversos sobre a informação de fonte.

As investigações precedentes sobre os "modos de referir-se ao discurso do outro" foram realizadas na Universidade de Stendhal, Grenoble, III, França, por Françoise Boch e Francis Grossmann, do LIDILEM (Laboratório de Didactica de 
Língua Estrangeira e Materna $)^{4}$. No Brasil, há poucos estudos sobre o tema, no entanto, podemos destacar as investigações realizadas na Pontifícia Universidade Católica de Minas Gerais (PUC-Minas) e na Universidade Estadual de Campinas (Unicamp), sob a coordenação geral de Angela Kleiman e Maria de Lourdes Matêncio Meirelles, do Núcleo Letramento do Professor. Os trabalhos realizados na PUC-Minas, por exemplo, estiveram mais interessados nas retextualizações de textos escritos teóricos em atividades de produção escrita na universidade e priorizaram resultados relacionados ao letramento de professores, através do exame da apropriação dos gêneros acadêmicos, por exemplo, as resenhas.

Para este estudo, particularmente, vamos revisar com mais detalhes os resultados da experiência francesa, tendo em vista o seu foco na citação e na heterogeneidade da prática discursiva da citação por especialistas e estudantes. Boch \& Grossmann (2002, p. 100-101) partem da ideia de que os modos de referência ao discurso do outro são bastante variados, sendo a citação apenas uma entre as diferentes modalidades de referência. Os autores, com base na análise de um corpus de 31 (trinta e um) relatórios de alunos franceses do $2^{\circ}$ ano Universitário, em comparação com um corpus de artigos de especialistas, conclui que os principais tipos de discurso reportado, ou modos de referência ao discurso do outro, presentes no material analisado são: citação, reformulação e evocação. Para os autores, o escritor da ciência, referindo-se ao discurso do outro, indica que resume, reformula ou cita: a citação cria um espaço autônomo no plano enunciativo; a reformulação permite ao escritor integrar a fala do outro em seu próprio dizer, assumindo-a do ponto de vista enunciativo e a evocação permite colocar em segundo plano os conhecimentos compartilhados, ou os elementos não essenciais, inscrevendo, ao mesmo tempo, a pesquisa em um espaço epistêmico identificável - da reformulação e da citação, que traduzem, cada uma a seu modo, uma maneira específica de se apoiar no dizer do outro.

Em diálogo com a perspectiva de Antoine Compagnon, da citação como trabalho, as categorias acima mencionadas podem ser resumidas como um estado de citação na escrita de pesquisa, em que a citação é a parte solta, recortada do texto-fonte, um fragmento de texto a ser citado, porém ainda não inserido, não é enxerto. A reformulação é o trabalho, a operação linguística, geralmente por meio de paráfrases, em que a parte recortada está em processo de ancoragem em um textodestino, por meio da operação da reformulação ou da paráfrase. Nesse caso, o autor repete com suas próprias palavras o pensamento do autor do texto fonte. Por fim, a evocação é a citação com vida própria em outro corpo, o enxerto em seu estado de vida própria. Nesse caso, o fragmento passa a constituir, sob a forma de uma

\footnotetext{
4 Laboratoire de Didactique de Langue Etrangère et Maternelle
} 
intertextualidade constitutiva, implícita, o discurso do autor da citação ou da escrita da pesquisa que acolheu a citação.

A seguir, mostramos um quadro síntese dos modos de referência descritos por Boch \& Grossmann (2002, p.101), incluindo as características de suas manifestações na escrita da pesquisa de especialistas e de estudantes.

\section{Tipos de referências}

\begin{tabular}{|c|c|c|}
\hline CITAÇÃO & REFORMULAÇÃO & EVOCAÇÃO \\
\hline $\begin{array}{l}\text { Marcas, geralmente escriturais, } \\
\text { como aspas, itálico ou bloco tipo- } \\
\text { gráfico, permitem identificar um } \\
\text { segmento do texto como extraído } \\
\text { de uma fonte externa; essas mar- } \\
\text { cas podem, às vezes, ser substitu- } \\
\text { ídas por comentários metalinguís- } \\
\text { ticos: eu cito X..., para retomar as } \\
\text { palavras de X.... }\end{array}$ & $\begin{array}{l}\text { Presença de marcas introdutórias } \\
\text { do discurso reportado (segundo } \\
X \ldots \text { de acordo com X..., para X..., } \\
\text { como X afirma..., como X pretende..., } \\
\text { etc.). } \\
\text { Ausência de marcas escriturais } \\
\text { tais como aspas (ou verbais, como } \\
\text { eu cito X, para retomar as palavras } \\
\text { de X). }\end{array}$ & $\begin{array}{l}\text { Ausência de marcas introdutó- } \\
\text { rias de discurso reportado (tais } \\
\text { como: segundo } X \text {, como afirma } X \text {, } \\
\text { ou equivalentes). } \\
\text { Ausência de desenvolvimento } \\
\text { temático do dizer do outro. }\end{array}$ \\
\hline $\begin{array}{l}\text { Autonomia enunciativa do seg- } \\
\text { mento citado (salvo no caso da } \\
\text { "ilbota citacional"). }\end{array}$ & $\begin{array}{l}\text { O discurso do outro é integrado } \\
\text { no discurso de quem escreve e não } \\
\text { tem autonomia enunciativa. }\end{array}$ & $\begin{array}{l}\text { Presença de um nome próprio de } \\
\text { autor, frequentemente com data } \\
\text { à qual o autor do artigo se refe- } \\
\text { re, sem precisar o teor do texto. }\end{array}$ \\
\hline
\end{tabular}

As práticas de referência por intermédio da evocação e a da reformulação, conforme as definições apresentadas por Boch \& Grossman (2002), sugerem que os sujeitos citantes, ao fazerem suas citações, apropriam-se do discurso do outro, e que à proporção que assumem tal discurso como próprio, operam no sentido de fazer compartilhar o discurso fonte, assim como a informação extraída desse discurso, transformando-a em uma parte inequívoca de seus próprios textos.

Em uma investigação realizada na revista Langages, os autores mostraram que a evocação é manifestada em $51 \%$ dos artigos e a reformulação em $34 \%$ das publicações, e no que diz respeito ao discurso reportado, a reformulação com a data de publicação entre parênteses é ainda mais valorizada pelos especialistas. Por outro lado, a citação é pouco frequente, em apenas 14\% das publicações. Nos 31 relatórios dos estudantes universitários, os autores constataram uma situação quase oposta, já que nos referidos textos há uma supervalorização da citação em relação à reformulação, ou seja, $71 \%$ contra $35 \%$. Nos textos dos estudantes, a evocação é pouco valorizada, com apenas $13 \%$ das referências ao discurso do outro. 
Por que a citação é uma prática utilizada pelos estudantes e menos utilizada pelos especialistas? Os autores elaboraram várias hipóteses, porém destaco uma que nos parece uma explicação de grande fôlego e que pode nos ajudar a entender essa complexidade em vários outros estudantes:

A citação de um autor autorizado permite ao principiante, mais do que a reformulação, fundamentar ou valorizar seu dizer; essa função, que pode aparecer, com efeito, ligado a restrições sociolinguísticas, a formas de insegurança que só um melhor domínio dos conteúdos, mas também uma mudança de lugar permite controlar. (BOCH \& GROSSMANN, 2002 p.102-103)

A partir desse pressuposto, podemos concluir que o recurso da citação, no qual se apoia frequentemente o produtor de textos na universidade, pode conduzir para outra forma de tomada de consciência, ligada aos aspectos mais técnicos, em particular no plano linguístico, em que à proporção que o escritor ganha maturidade ou familiaridade com as fontes teóricas, mais capaz ele se torna de gerenciar e de integrar a citação a seu texto; ao contrário, quanto menos esses escritores têm familiaridade com a informação citada, menos habilitado o aluno se torna para integrar a citação. Por exemplo, o conhecimento dos códigos específicos ligados ao discurso fonte e ao discurso citado permite a aluno e professor em formação observar as diferentes formas de inserção das citações e compreender melhor como se efetuam as demarcações de vozes, oferecendo os meios para construir seus próprios "sistemas de posições enunciativas" (BOCH \& GROSSMANN, 2002 p.102). Dessa forma, o conhecimento da técnica de citação, tal como é amplamente prescrito nas normas técnicas da ABNT (Associação Brasileira de Normas Técnicas), da NP 405 (Norma Portuguesa sobre referências bibliográficas) e da APA (American Psychological Association), assim como a mera exigência institucional de citações em trabalhos de conclusão de curso não são suficientes para garantir ao estudante a maturidade de citar, integrando as informações novas a seu texto e fazendo que a citação seja parte inequívoca, reformulada e integrada ao corpo do texto.

\section{ABORDAGEM METODOLÓGICA}

\subsection{A pesquisa em linguística aplicada}

A pesquisa em Linguística Aplicada (LA) se ocupa do estudo dos problemas sociais de comunicação em contextos específicos. Em função disso, a pesquisa em LA acarreta, muitas vezes, uma tripla expansão: (i) a expansão dos dados empíricos, em 
função das condições naturais de realização da pesquisa; (II) a expansão das metodologias, em função dos diversos objetivos específicos valorizados; (iii) a expansão das disciplinasfonte (multidisciplinaridade), tendo em vista a produção de categorias que expliquem o objeto, levando em conta a complexidade dos problemas abordados (KLEIMAN, 1998, p. 52).

\begin{abstract}
Para esta investigação, a expansão dos dados é a valorização das práticas de citação em diferentes textos e contextos acadêmicos, a saber, as citações de estudantes brasileiros da Universidade do Estado da Bahia (UNEB) e de estudantes portugueses da Universidade de Aveiro (UA) e da Universidade do Porto (UP). A expansão das metodologias é a diversidade dos métodos de coletas e de análise no exame de documentos escritos: trabalhos de final de curso, relatórios de iniciação científica e resumos ampliados e, finalmente, a expansão das disciplinas-fonte é o apoio em conceitos de áreas distintas, porém convergentes, a saber, o conceito de enunciação, da linguística do discurso, e o conceito de letramento, da linguística aplicada e da educação. Os instrumentos e os percursos de coleta e análise de dados são definidos em função das contingências empíricas: da natureza do objeto estudado, do tipo de população e de outros fatores locais que ajudam na explicação do fenômeno.
\end{abstract}

\title{
2.2. A pesquisa qualitativa
}

A abordagem qualitativa é uma orientação teórico-metodológica de pesquisa que leva em conta o dinamismo das práticas sociais focalizadas e, por isso, é amplamente relevante para o desenvolvimento das pesquisas nas ciências sociais e humanas, incluindo as pesquisas em linguística aplicada e ciência da informação aplicada. De acordo com o conjunto das definições formuladas por vários autores (ERICKSON, 1989/2001; ANDRÉ, 1995; DENZIN \& LINCOLN, 1998), esse tipo de pesquisa possui algumas características que, a nosso ver, são centrais para a configuração desta proposta, a saber:
a) As condições reais da pesquisa
b) Multiplicidade de instrumentos
c) Análise qualitativa

A característica apontada em (a) considera que a pesquisa qualitativa focaliza preferencialmente o ambiente natural no qual são desenvolvidas as práticas sociais ou fontes geradoras de dados potenciais, ou seja, os dados relevantes para a constituição do objeto de investigação (ERICKSON, 2001). A rigor, não há manipulação de variáveis nem tratamento experimental e sim uma investigação do fenômeno em seu babitat natural (ANDRÉ, 1995; DENZIN \& LINCOLN, 1998). Com base nessa orientação, o pesquisador deve mergulhar nos eventos cotidianos e registrar cuidadosamente, 
por meio dos instrumentos variados, as manifestações dos grupos ou indivíduos pesquisados.

A característica apontada em (b) considera que os registros dos eventos cotidianos geradores de dados deverão possuir "evidências mais fortes" (ERICKSON, 2001: p. 14) se forem coletados por meio de instrumentos variados. Com base nessa orientação, o pesquisador, uma vez mergulhado na realidade, realiza múltiplas bricolagens, ou seja, deve ser capaz de realizar diversos ajustes no decorrer da pesquisa (DENZIN \& LINCOLN, 1998), tendo em vista o conhecimento amplo dos eventos focalizados. Os ajustes tendem a se concretizar por meio do emprego de diversas técnicas de coleta/ análise como, por exemplo, a "triangulação" das evidências confirmadas em relação ao foco central: análise de citações, escrita de pesquisa, depoimentos ou comentários.

A característica (c) considera que os registros dos eventos cotidianos geradores de dados deverão ser analisados com mais ênfase na qualidade e com menos ênfase na quantidade (ERICKSON, 2001). Essa orientação sugere que o enfoque quantitativo não é a característica fundamental da pesquisa dita qualitativa (ANDRÉ, 1995), uma vez que essas abordagens podem se complementar, por exemplo, quando a quantificação de ocorrências explica, qualitativamente, o fenômeno das práticas de citação investigadas. Em alguns casos específicos, como afirma Gramsci (1995, p. 34), "a quantidade pode ter um significado bastante particular, que não pode ser confundido com soma aritmética, porque indica maior ou menor homogeneidade, coerência, logicidade, etc.". Dessa forma, a interpretação dos dados nesta pesquisa deve se orientar pelo enfoque qualitativo, mas sem descartar as quantificações, quando se mostrarem pertinentes.

Enfim, a abordagem qualitativa é uma orientação pertinente para o estudo das práticas citantes de estudantes universitários, porque permite investigar, a partir da triangulação de técnicas de coleta e de análise, as práticas reais de citação em trabalhos acadêmicos. No contexto real de ensino da escrita de pesquisa, portanto, a citação é um objeto privilegiado para uma compreensão, para além da observação das normas técnicas, da complexidade que envolve a inserção de estudantes de diferentes contextos acadêmicos, para examinar em detalhe os problemas de leitura e do acesso à informação científica e para apoiar uma revisão da política de ensino da produção escrita na universidade.

\subsection{A triangulação em pesquisa qualitativa}

No modelo positivista, a "triangulação" é definida como uma técnica de validação dos dados de pesquisa, adotando uma acepção clássica de validade, ou seja, a que busca a essência do fenômeno na relação entre o real e a teorização sobre 
o real (SPINK, 1993). No modelo qualitativo, por outro lado, a "triangulação" é vista como uma ferramenta de pesquisa, devendo ser entendida e apropriada como um instrumento valioso na ampliação das evidências, na organização e análise dos dados (DENZIN \& LINCOLN, 1998). A "triangulação", enquanto instrumento da pesquisa qualitativa, é configurada a partir da combinação de múltiplas técnicas para mapeamento dos dados e do cruzamento de múltiplas fontes e análises, visando ao enriquecimento e ao fortalecimento das evidências e das interpretações. Como aponta Erickson,

[...] na medida em que a análise vai sendo realizada, e as intuições acerca dos padrões desenvolvidos com base em notas de campo são cruzadas e confirmadas em relação aos dados das entrevistas ou documentos locais, tem-se uma evidência mais forte do que se a evidência viesse apenas de uma fonte de informação. (ERICKSON, 2001, p.14)

Essa multiplicidade de técnicas se justifica, no contexto deste trabalho, porque a realidade é complexa e, sendo assim, a coleta das citações, em contextos luso-brasileiros de práticas de citações, pode ser mais bem realizada a partir do emprego de variados instrumentos de pesquisa como tipos de citações, escritas de pesquisa e entrevistas. Além disso, a interpretação dos dados é mais enriquecida por se basear no cruzamento entre a apropriação dos conceitos pelos estudantes e o controle das citações em diferentes instâncias enunciativas. Com base nessa orientação, portanto, a "triangulação" se configura, nesta metodologia, a partir do emprego de múltiplos instrumentos e de variadas fontes geradoras de dados:

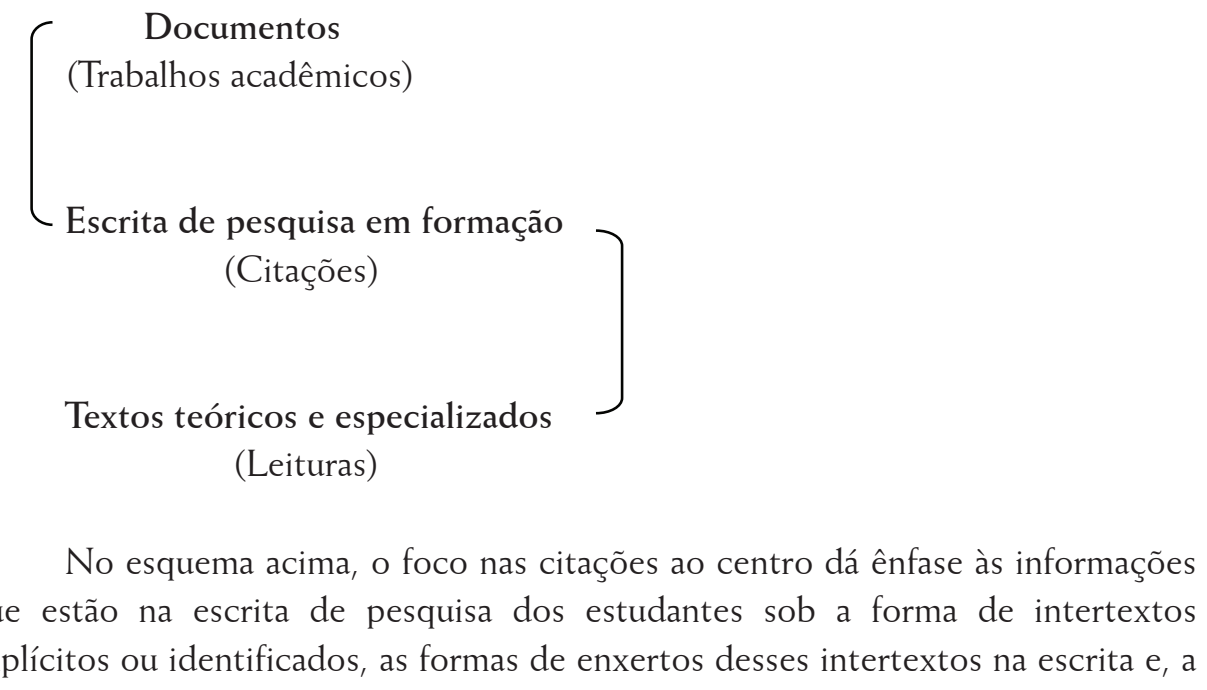


partir desse ponto, levanta respostas e hipóteses sobre: como os estudantes citam? Quais as reformulações feitas nas informações e conceitos citados? Que identidade é construída entre os autores da citação e as fontes citadas? Como o contexto de produção orienta o aprendizado da citação e quais apontamentos para melhorar o ensino da escrita de pesquisa na Universidade?

\section{RESULTADOS ALCANÇADOS}

Os resultados envolvem, em primeiro lugar, uma descrição densa do corpus analisado e, em segundo lugar, uma quantificação com descrição e interpretação dos resultados das ocorrências no contexto brasileiro e português, considerando as universidades focalizadas.

Os dados trabalhados foram levantados a partir de uma busca em repositórios de bibliotecas, por exemplo, 10 Trabalhos de Conclusão de Curso (TCC) produzidos por estudantes de licenciatura em Pedagogia do Departamento de Educação da Universidade do Estado da Bahia (UNEB, Bahia, Brasil), 10 Trabalhos de Conclusão de Curso do Instituto de Estudos da Linguagem (IEL), da Universidade Estadual de Campinas (UNICAMP, Campinas-SP, Brasil) e 10 Relatórios de Estágio, produzidos por estudantes de licenciaturas da Faculdade de Letras da Universidade do Porto (FLUP, Porto, Portugal). A rigor, são contextos de formação universitária que possuem excelentes repositórios à disposição dos estudantes, de forma que a condição de leitura e de acesso à informação teórica está entre as melhores de cada país ${ }^{5}$. Nos referidos textos acadêmicos, focalizamos, particularmente, os capítulos intitulados de "enquadramento teórico" do trabalho, ou seja, uma parte em que as referências ao discurso do outro são demasiadamente visíveis e de fácil acesso. No total, foram recolhidas 249 referências nos TCC da UNEB, 195 referências nos TCC da UNICAMP e 255 referências nos relatórios de final de curso da FLUP.

\subsection{Trabalhos acadêmicos}

A seguir, mostraremos um quadro geral com os títulos dos documentos examinados na pesquisa.

5 http://www.iel.unicamp.br/biblioteca/teses.php (Biblioteca Digital do Instituto de Estudos da Linguagem - IEL/Unicamp) e https://repositorio-aberto.up.pt/handle/10216/1740 (Repositório Aberto da Faculdade de Letras da Universidade do Porto - FLUP-UP). 


\section{Trabalhos acadêmicos}

\begin{tabular}{|c|c|c|}
\hline UNEB & UNICAMP & FLUP \\
\hline $\begin{array}{l}\text { O conceito de aprendizagem de Skinner } \\
\text { e Vygotsky: um diálogo possível }\end{array}$ & $\begin{array}{l}\text { A construção da identidade em alunos } \\
\text { migrantes na Sala de aula }\end{array}$ & $\begin{array}{l}\text { O relato de discurso como estratégia } \\
\text { de desenvolvimento da competência } \\
\text { oral em PLE }\end{array}$ \\
\hline $\begin{array}{l}\text { Literatura infantil e a identidade da } \\
\text { criança negra: Construção ou negação? }\end{array}$ & $\begin{array}{l}\text { A formação do leitor no ensino fun- } \\
\text { damental II: leitura situada em livros } \\
\text { didáticos de Lingua portuguesa }\end{array}$ & $\begin{array}{l}\text { A imagem nas aulas de lingua: poten- } \\
\text { cialidades didáticas e possibilidades de } \\
\text { aplicação }\end{array}$ \\
\hline $\begin{array}{l}\text { Música: A importância pedagógica } \\
\text { para o ensino fundamental }\end{array}$ & $\begin{array}{l}\text { Algumas representações do ensino } \\
\text { público: uma análise dos cadernos de } \\
\text { língua portuguesa em (des)uso. }\end{array}$ & $\begin{array}{l}\text { "Se for sempre o professor a falar nós } \\
\text { adormecemos...": ouvir as vozes dos } \\
\text { alunos para ensinar História e Geo- } \\
\text { grafia no } 3^{\circ} \text { Ciclo do Ensino Básico }\end{array}$ \\
\hline $\begin{array}{l}\text { Reflexões sobre a relação família - es- } \\
\text { cola no Processo de aprendizagem da } \\
\text { criança de educação Infantil }\end{array}$ & $\begin{array}{l}\text { A linguística e o ensino de ciência na } \\
\text { escola. }\end{array}$ & $\begin{array}{l}\text { A Utilização dos Materiais Icono- } \\
\text { gráficos no Ensino da Língua Portu- } \\
\text { guesa no Nivel A1. } 1 .\end{array}$ \\
\hline $\begin{array}{l}\text { A implementaçãa da lei } n^{0} 11.769 / 2008 \\
e \text { as contribuições da educação musical } \\
\text { nas classes infantis na cidade de Sal- } \\
\text { vador }\end{array}$ & $\begin{array}{l}\text { A propaganda política impressa: uma } \\
\text { análise comparativa das estratégias de } \\
\text { apresentação e persuasão }\end{array}$ & $\begin{array}{l}\text { Somos todos escritores, só que alguns } \\
\text { escrevem e outros não. Oficinas de } \\
\text { Escrita em História e em Geografia: } \\
\text { uma experiência pedagógica }\end{array}$ \\
\hline $\begin{array}{l}\text { Da oralidade à escrita: os contos de fa- } \\
\text { das no processo de alfabetização }\end{array}$ & $\begin{array}{l}\text { Representação do Analfabeto no Filme } \\
\text { Central do Brasil }\end{array}$ & $\begin{array}{l}\text { Organização Textual: A escrita por } \\
\text { parágrafos através da técnica What- } \\
\text {-Why-How }\end{array}$ \\
\hline $\begin{array}{l}\text { A literatura de cordel como uma ferra- } \\
\text { menta para a aprendizagem de grupos } \\
\text { sociais no município de Santa Bárbara }\end{array}$ & $\begin{array}{l}\text { A respeito das posições-sujeito do profes- } \\
\text { sor: uma análise discursiva das relações } \\
\text { em sala de aula }\end{array}$ & $\begin{array}{l}\text { "App(lica-te)": As aplicações móveis } \\
\text { como suporte às visitas de estudo }\end{array}$ \\
\hline $\begin{array}{l}\text { A produção de vídeos na educação de } \\
\text { jovens e adultos em uma perspectiva } \\
\text { sócio-construtivista }\end{array}$ & $\begin{array}{l}\text { As Expressões de Gênero nas Perfor- } \\
\text { mances de Madonna }\end{array}$ & $\begin{array}{l}\text { 2. }{ }^{\circ} \text { Ciclo de Estudos em Português Lin- } \\
\text { gua Segunda / Lingua Estrangeira }\end{array}$ \\
\hline $\begin{array}{l}\text { Lunaris de Carlos ribeiro: diálogo entre } \\
\text { a Estética pós-moderna e outros movi- } \\
\text { mentos Literários }\end{array}$ & $\begin{array}{l}\text { As influências de um conto em um } \\
\text { discurso infantil: Uma análise em "a } \\
\text { canção do sul" }\end{array}$ & $\begin{array}{l}\text { A aprendizagem cooperativa: uma } \\
\text { metodologia aplicada nas disciplinas } \\
\text { de História e Geografia }\end{array}$ \\
\hline $\begin{array}{l}\text { A vida privada de negros pioneiros no } \\
\text { povoamento de Teixeira de Freitas na } \\
\text { década de } 1960\end{array}$ & $\begin{array}{l}\text { Considerações sobre o comportamento } \\
\text { discursivo de uma professora surda } \\
\text { bilingue }\end{array}$ & $\begin{array}{l}\text { "Asas on Gaiolas?" Da reflexão te- } \\
\text { órica à prática escolar no ensino da } \\
\text { História e da Geografia. }\end{array}$ \\
\hline
\end{tabular}

Os documentos analisados são, portanto, textos acadêmicos, com temáticas diversificadas, em educação, linguística aplicada, linguística e literatura. São todos trabalhos produzidos como requisitos para finalização de curso, nas licenciaturas ou especializações, cuja conclusão depende da finalização e defesa pública sob o 
formato de uma monografia ou relatório de estágio. Em todos os trabalhos há a seção que trata dos pressupostos teóricos da pesquisa. Nos trabalhos produzidos pelos estudantes da Universidade do Estado da Bahia (UNEB) não há um capítulo com o título "Pressupostos teóricos", no entanto, há tópicos em que são desenvolvidos os conceitos principais da pesquisa, por exemplo, "2. Aprendizagem segundo Skinner". No conjunto das monografias levantadas, apenas 01 (um) trabalho da UNEB empregou o subtítulo "Pressupostos teóricos", os demais parecem não ter essa orientação ou exigência formal. Nos trabalhos produzidos pelos estudantes da Universidade Estadual de Campinas (UNICAMP), a indicação do título "Pressupostos teóricos" é valorizada, em 05 (cinco) dos 10 trabalhos analisados, porém, sem uniformidade: "Arcabouço teórico", "Quadro teórico", "Pressupostos teóricos", "Fundamentação teórica" e "Resumo teórico e bibliográfico". Nos trabalhos produzidos pelos estudantes da Faculdade de Letras da Universidade do Porto (FLUP), o titulo preferido é "Enquadramento teórico", valorizado por 09 (nove) dos trabalhos acadêmicos analisados. No total, apenas 01 (um) trabalho não possui o título dos pressupostos teóricos, optando por indicar apenas "Alguns conceitos...", seguindo a tendência das monografias brasileiras.

A recolha ou coleta das citações foi feita, portanto, nessa parte dos trabalhos, e esse procedimento se deveu ao fato de que na escrita de pesquisa é uma orientação universal que o primeiro capítulo seja dedicado aos pressupostos teóricos, seja qual for a variação desses títulos; portanto, é também nesse lugar dos textos que podemos encontrar um número maior de referências ao discurso teórico e, da mesma forma, as relações que os estudantes estabelecem com esse discurso, ao citá-lo, reformálo ou evocá-lo em seus textos próprios. O contato com esse material, portanto, nos permitiu fazer um mapeamento sobre os modos de referência ao discurso do outro, incluindo as citações, no conjunto de trabalhos acadêmicos levantados. Esse quadro foi o ponto de partida para a busca de resposta relacionada às condições sociais da leitura, da hipótese que se fortaleceu durante a realização da pesquisa de que a história de letramento dos estudantes e de identidades com os intertextos são uma condição fundamental para as citações mais bem reformuladas e enxertadas na escrita de pesquisa e, logo, como apoio à aquisição do letramento e para a inclusão de jovens na Universidade.

\subsection{As referências ao discurso do outro no Brasil e em Portugal}

No quadro a seguir temos os "modos de referência ao discurso do outro", conforme o levantamento nos documentos de trabalho acadêmico descritos no item 
anterior. O título do gráfico é coerente com as categorias sugeridas por Boch e Grossmann (2002), e a citação se refere às ocorrências em que os estudantes o trecho extraído do texto-fonte é inserido na escrita integralmente, sem alterações do sentido e da forma. É a citação propriamente dita. Na citação por reformulação os estudantes não omitem a fonte, sendo o texto parafraseado, com o pensamento e as informações do texto fonte inseridos com as palavras dos estudantes - quanto mais conhecimento do assunto e posse de um vocabulário, mais esse tipo de referência tende a aparecer nessa escrita. A evocação, referência às ideias do outro ou do texto fonte sem marcas do discurso reportado - tais como segundo $X$, como afirma $X$ ou marcas equivalentes - são mais comuns na citação e na reformulação.

Nos 10 trabalhos de cada Universidade, identificamos 699 (seiscentos e noventa e nove referências), sendo 249 nos trabalhos dos estudantes da UNEB, 195 referências nos trabalhos dos estudantes da UNICAMP e 255 nos trabalhos dos estudantes da FLUP.

\section{Referências por Universidades}

\begin{tabular}{lcccc}
\hline UNIVERSIDADES/REFE- & CITAÇÃO & REFORMULAÇÃO & EVOCAÇÃO & T. GERAL \\
RENCIAS & 159 & 63 & 23 & 245 \\
UNEB & 126 & 62 & 7 & 195 \\
UNICAMP & 157 & 86 & 12 & 255 \\
FLUP & 442 & 211 & 42 & 695 \\
\hline TOTAL EM REFERÊNCIAS & &
\end{tabular}

$\mathrm{Na}$ análise, a seguir, vamos descrever os percentuais de cada um dos modos de referência ou tipos de citação do discurso teórico, conforme as ocorrências em cada Universidade. Além disso, vamos proceder a uma análise mais interpretativa da relação entre os modos de citação nas universidades brasileiras e portuguesas e, na medida do possível, retomando os resultados da realidade francesa, tal como foram apresentados por Françoise Boch e por Francis Grossmann. A partir disso, será oportuno emitir algumas reflexões sob a forma de uma conclusão prospectiva sobre o que esses resultados apontam para o aprendizado da citação e da escrita da pesquisa e para o futuro do letramento na educação superior no Brasil e na Europa. 


\section{MODOS DE REFERÊNCIA AO DISCURSO DO OUTRO}

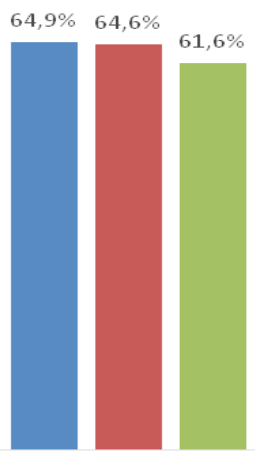

CITAÇÃO

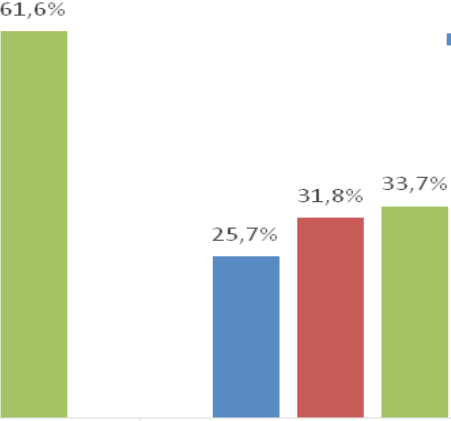

REFORMULAÇÃO
-UNEB EUNICAMP ELUP

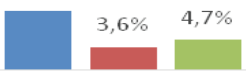

EVOCAÇÃO

\section{Citação}

A citação é inserida no texto dos estudantes sob a forma de um intertexto totalmente explícito, ou seja, os segmentos são citados por meio de marcadores de polifonia como "aspas", itálico e indicação de página da obra de referência. Por isso, permite identificar com mais precisão a relação entre o texto do estudante e o texto teórico do qual extraiu o segmento citado. As citações são normalmente introduzidas por articuladores intertextuais do tipo: conforme $X$, segundo $Y$, como afirma $Z$, etc. Na escrita de pesquisa, portanto, a citação aparece como um enunciado autônomo, não necessariamente incoerente, sem unidade, mas explicitamente definido como parte extraída de outro texto.

No computo geral dos dados, a citação como modalidade de referência se configurou da seguinte forma:

No âmbito desta discussão, é importante considerar o que Orlandi (1999, p.49) escreve com relação ao sujeito:

Ele [o sujeito] é materialmente dividido desde sua constituição: ele é sujeito de e é sujeito à. Ele é sujeito à língua e à história, pois para se constituir para (se) produzir sentidos ele é afetado por elas. Ele é assim determinado, pois se não sofrer os efeitos do simbólico, ou seja, se ele não se submeter à língua e à história ele não se constitui, ele não fala, não produz sentidos.

\section{Figura 1 Citação/Unicamp 5}


Conforme a figura acima, a citação é inserida através do articulador " ...o que x escreve em relação a...". A citação, enquanto parte deslocada da fonte, é a modalidade de referência preferida pela maioria dos estudantes portugueses e brasileiros. $\mathrm{Na}$ Universidade do Estado da Bahia (UNEB), 64,9\%, na Universidade Estadual de Campinas (UNICAMP), 64,6\% e na Faculdade de Letras da Universidade do Porto (FLUP), 61,6\%.

\section{Reformulação}

A reformulação, assim como ocorre nas citações, é introduzida por meio de articuladores intertextuais já descritos, ou seja, com a presença de marcas introdutórias do discurso reportado "com sustenta x...", "o conceito de x...", "segundo x...", "como defende x...", "para x...", "x também vai advogar que...", etc. Notamos também que nas reformulações dos estudantes portugueses, embora os textos citados sejam inseridos com as palavras dos autores dos trabalhos acadêmicos, ou seja, sem marcas explícitas de polifonia, em quase todas as ocorrências há, tal como nas citações autônomas, a indicação de páginas. Essa tendência não se repete na escrita dos estudantes brasileiros, já que nesses casos a indicação de página é mais frequente nas citações propriamente ditas ou autônomas e nas chamadas ilhotas citacionais, ou seja, indicando a fonte exata de certos termos ou expressões (Boch \& Grossmann, 2002).

No documento de normas técnicas de Portugal, "Citar e referenciar: estilo bibliográfico APA 6th", sobre a citação indireta, ou seja, as referências com palavras próprias, tal como a reformulação, é dito que "a transmissão do conhecimento dos autores dos documentos consultados deve ser sempre acompanhada da citação ao mesmo, ou seja, a referência em texto ao Apelido do autor, Ano de publicação e a localização (páginas)". (APA 6th, 2015, p.7).

Já no documento de normas técnicas do Brasil, "Guia de Normalização ABNT para referências e citações", divulgado pela Biblioteca Central da Unicamp, a indicação de página somente é exigida para as "citações diretas", já para as "citações indiretas", essa indicação não é obrigatória. A citação indireta, conforme o referido Guia, é, tal como a reformulação, uma paráfrase ou uma "reprodução livre de ideias de uma obra consultada, sendo que a indicação de páginas é facultativa ou opcional" (SBU- UNICAMP, 2008, p.34).

Assim, tanto os estudantes brasileiros, quanto os estudantes portugueses, estão em alguma medida seguindo as orientações técnicas de cada país e, por isso, a existência das diferenças quanto ao formato das reformulações de referências nos 
trabalhos acadêmicos analisados. Essas ocorrências, no entanto, parecem desfazer em parte o pressuposto de que as reformulações não têm autonomia enunciativa (BOCH \& GROSSMANN, 2002) em relação às suas fontes, visto que a indicação de página é, a nosso ver, uma indicação explícita de que, nos dados portugueses, mesmo a reformulação é um enunciado autônomo, ou seja, visualmente apartado do texto.

Também Traquina nota que a ideologia profissional, desenvolvida ao longo do tempo, define o jornalismo como um serviço público que fornece aos cidadãos a informação de que precisam para votar e participar em democracia, e age como guardião de defesa dos cidadãos contra eventuais abusos de poder. (Traquina, 2007).

Figura 2 Reformulação/FLUP 1

A reformulação, diferente da citação, aparece como uma prática de referência menos utilizada pelos estudantes de todas as universidades pesquisadas. Na UNEB, 27,7\%, na UNICAMP, 31,8\%, e na FLUP, 33,7\%. Nesse caso, as diferenças são pequenas; no entanto, há sinais de que os trabalhos dos estudantes portugueses da FLUP apresentaram uma pequena elevação do número de reformulações em relação aos trabalhos de estudantes brasileiros. Há, portanto, uma hipótese que não pode ser desprezada; por exemplo, a de que o trabalho acadêmico da FLUP, sob a modalidade de relatório de estágio, possui um número de páginas superior aos trabalhos acadêmicos na modalidade de monografias de licenciaturas das universidades brasileiras. No Brasil, os estudantes de graduação produzem monografias com número de 50 e 60 páginas em média. Além disso, os trabalhos de final de curso da FLUP estão no nível da licenciatura e da especialização, enquanto os trabalhos de conclusão de curso das universidades brasileiras estão no nível da graduação ou das licenciaturas, na nomenclatura portuguesa.

Do ponto de vista de uma análise qualitativa, as reformulações - como práticas que exigem mais familiaridade com as fontes, conhecimento e domínio das terminologias - permitem que os estudantes mais maduros ou que construíram maior identidade enunciativa com os discursos teóricos, por exemplo, possam reformular ou parafrasear mais o pensamento dos autores em seus textos. Logo, não parecem ser as condições materiais de acesso à leitura teórica uma condição suficiente para influenciar nas ocorrências quantitativas das reformulações, mas, sobretudo, o tempo de amadurecimento e a profundidade das leituras realizadas que permitem a apropriação das fontes letradas e, logo, a capacidade de inseri-las ou enxertá-las em textos escritos de pesquisa na Universidade. 


\section{Evocação}

A evocação é trazer à memória uma ideia ou o pensamento de um autor sem precisar a origem da fonte. Nos trabalhos acadêmicos analisados, a evocação é inserida nos trabalhos acadêmicos sem marcas de polifonia ("aspas" e itálicos), e sem as marcas de articulação intertextual como "segundo X", "como afirma x", etc. Há a presença de nomes próprios do autor ou apelido, entretanto, não há indicação explícita da referência, nem desenvolvimento temático do dizer do outro, conforme podemos ver no exemplo, a seguir.

Entende-se por pesquisa descritiva aquela que tem como objetivo descrever e caracterizar determinada população ou fenômeno, por meio de técnicas padronizadas de coleta de dados, como aplicação de questionários e observações sistemáticas (GIL, 2002).

\section{Figura 3 Evocação/UNEB1}

A evocação, tal como pressupunha Boch \& Grossmann (2002), é um modo de referência ao discurso do outro pouco explorado na escrita de pesquisa dos estudantes. Nos dados aqui apresentados, os estudantes da UNEB, realizaram 9,4 de referências por evocação, os estudantes da UNICAMP realizaram 3,6\% e os estudantes da FLUP 4,6\%. Os autores chegaram à conclusão de que essa demanda de referência é muito mais recorrente na prática dos especialistas e em publicação de artigos para revistas, nas quais os pares especialistas são a audiência em potencial. Há, nesse caso, portanto, um tipo de interlocução em que o posicionamento dos autores acerca de temas de interesses dos periódicos e das particularidades dos campos ou projetos científicos é central - diferentemente do que ocorre com os pesquisadores iniciantes, cuja produção da escrita de pesquisa é altamente interditada pelos discursos normalizadores e tende a ter como audiência quase exclusiva uma banca de examinadores. Essas tensões, a nosso ver, influenciam significativamente na escolha dos modos de referência ao discurso do outro pelos estudantes, por exemplo, quando acreditam que escrever na universidade é quase sempre citar e quase nunca reformular ou evocar ideias.

Esse ponto é de fato crucial para pensarmos o futuro de ensino da escrita de pesquisa, uma vez que, se por um lado os estudantes, em função do seu tempo de leitura teórica, são pouco potencializados para as reformulações e evocações de ideias, por outro, a sobrecarga de normas, as exigências institucionais, os medos dos plágios, podem estar inibindo o exercício fabuloso da apropriação de conceitos, 
por exemplo, por meio das reformulações com palavras próprias. A questão é se essa competência de revozear ideias de especialistas pode ser bem sucedida sem uma devida identidade enunciativa com as fontes teóricas e se essa identidade enunciativa pode ser construída em fase de iniciação à escrita de pesquisa. Então, cabe-nos perguntar se as universidades podem reinventar seus métodos para que estudantes ainda jovens possam ter uma trajetória equilibrada entre as boas e certas práticas de leitura teórica, tendo em vista, o acesso aos infratextos e intertextos que dão suportes às escritas teóricas de referências. Em conclusão prévia, portanto, vale dizer que as boas citações, as boas escritas de pesquisa, são, em alguma medida, dependentes da ampliação da biblioteca de referência dos estudantes e, da mesma forma, do acervo conceitual e terminológico que podem ser evocados em atividades de citação escrita ou oral. Sem essa condição, parece-nos que exigir dos estudantes de graduação ou das licenciaturas outro padrão de referência, além da citação, é uma tarefa inútil.

\section{CONCLUSÃO PROSPECTIVA}

Começamos a realizar esta investigação com uma hipótese central de que os modos de referência do discurso do outro na escrita de pesquisa, incluindo a prática de citação, são objetos privilegiados à disposição dos pesquisadores do letramento acadêmico informacional na busca de respostas sobre demandas de estudos sobre a inclusão de jovens na educação superior e, particularmente, nas práticas de letramento valorizadas na cultura universitária. Através de um foco na citação, nós investigadores podemos revelar problemas de leituras, no que tange às capacidades de localizar intertextos, ou seja, a biblioteca pressuposta no discurso escrito teórico, e infratextos, ou seja, os contextos em que tais obras fazem sentido ou não (GUIBERT, 2001); entretanto, mais amplamente, podemos interpretar como as instituições de ensino superior estão possibilitando a apropriação da informação científica por diferentes estudantes, em diferentes contextos de educação superior no Brasil e em Portugal.

A citação autônoma, enquanto recurso de referência direta e explícita ao discurso teórico, é a modalidade de referência mais recorrente nos trabalhos acadêmicos examinados neste trabalho, ou seja, uma tendência já comprovada nas investigações realizadas com estudantes franceses, sob a coordenação dos pesquisadores Françoise Boch e Francis Grossmann, tal como já descritas antes. 
A amostragem das pesquisas até aqui realizadas, embora seja um bom indicador dessa tendência, não responde ainda por que os estudantes em fase de iniciação científica, em cursos de licenciaturas e especialização, citam tanto? Os pesquisadores franceses, a propósito de seus resultados estatísticos, apontaram algumas hipóteses que merecem ser destacadas:

- Trata-se, de fato, de um primeiro contato com a retórica própria do discurso científico: de um ponto de vista linguístico, essa "distância" se traduziria mais espontaneamente pela justaposição (sintática e enunciativa) do discurso do estudante e daquele que ele empresta - ou seja, a citação do que pela fusão, característica da reformulação.

- Pode-se supor, aliás, que a orientação "coloque seus conhecimentos e cite suas fontes", sem outras explicações, é entendida como a injunção "faça citações". É quase certo, com efeito, que, para os estudantes, a citação representa a forma canônica de referência ao discurso do outro, sem dúvida porque o estudante não está familiarizado com a prática da reformulação, frequentemente apresentada no discurso do professor como a da paráfrase.

- Enfim, a citação de um autor autorizado permite ao principiante, mais do que a reformulação, fundamentar ou valorizar seu dizer; essa função, que pode aparecer, com efeito, ligada a restrições sociolinguísticas, a formas de insegurança que só um melhor domínio dos conteúdos - mas também uma mudança de lugar - permite controlar.

(BOCH \& GROSSMANN, 2002, p.102-103)

As hipóteses acima são pertinentes e coerentes com as interpretações propostas nesse trabalho com os estudantes brasileiros e portugueses, no qual destacamos a priori o fato de que, no estado da iniciação à escrita de pesquisa, a escrita é, a rigor, a referência ao discurso do outro, e é algo novo a ser aprendido. O estudante das licenciaturas, embora letrado - no sentido universal do termo -, no âmbito do letramento social, acadêmico informacional, ainda está em processo de aquisição, daí ser correto supor que as restrições de ordem sociolinguística, a insegurança quando aos domínios dos conteúdos e também do contexto enunciativo da escrita de pesquisa, como acima destacam Boch e Grossmann, são aspectos que dificultam a prática da reformulação ou o "dizer com suas palavras" nos trabalhos acadêmicos das licenciaturas.

A partir desse pressuposto, podemos concluir que o recurso da citação, no qual se apoia frequentemente o produtor de textos na universidade, pode conduzir 
a outra forma de tomada de consciência, ligada aos aspectos mais técnicos, em particular no plano linguístico, no qual, à proporção que o escritor ganha maturidade ou familiaridade com as fontes teóricas, mais capaz ele se torna de gerenciar e de integrar a citação a seu texto. E ao contrário, quanto menos esses escritores têm familiaridade com a informação citada, menos habilitado o aluno se torna para integrar a citação. Por exemplo, o conhecimento dos códigos específicos ligados ao discurso fonte e ao discurso citado permite a aluno e professor em formação observar as diferentes formas de inserção das citações e compreender melhor como se efetuam as demarcações de vozes, oferecendo os meios para construir seus próprios sistemas de posições enunciativas (Boch \& Grossmann, 2002). Dessa forma, o conhecimento da técnica de citação, tal como é amplamente prescrito nas normas técnicas, a exemplo, da ABNT, da NP 405 e da APA, assim como a mera exigência institucional de citações em trabalhos de conclusão de curso não serão suficientes para garantir ao estudante a maturidade de citar, integrando as informações novas a seu texto e fazendo com que a citação seja parte inequívoca, reformulada, evocada e integrada ao corpo do texto.

A condição de leitura, materialmente definida pela qualidade e disponibilização do acervo, é apenas uma parte das condições de uso e de apropriação do discurso teórico, já que em duas universidades pesquisadas, particularmente a UNICAMP e a FLUP, as bibliotecas oferecem condições privilegiadas de leitura e pesquisa bibliográfica. O problema central, parece-nos, é como estabelecer mediações de leitura para que essa biblioteca física, recheadas de livros e de informações teóricas sofisticadas, seja suporte efetivo de conhecimento e de informações teóricas à disposição dos estudantes, em suas produções escritas, em especial, em seus trabalhos de final de curso.

A nosso ver, as universidades operam com a lógica do letramento universal e reproduzem a crença de que o mero contato dos estudantes com a escrita, com as fontes teóricas, já é suficiente para torná-los academicamente letrados. Os efeitos negativos dessa crença no acesso à informação teórica são muitos; o mais preocupante, porém, são as dificuldades com a escrita de pesquisa que os estudantes da graduação ou das licenciaturas levam para os cursos de pós-graduação, ao longo da vida.

Assim, a título de uma conclusão prospectiva, tendo em vista novos estudos sobre o tema e a ampliação dos modos de referência ao discurso e à informação teóricos, podemos sugerir algumas metodologias de ensino da escrita/leitura para melhorar a inclusão de estudantes iniciantes no letramento acadêmico informacional: 
- As leituras orientadas: as universidades devem realizar com mais frequência leituras orientadas nos cursos de graduação e nas licenciaturas. Os professores universitários, os supervisores e orientadores devem experimentar mais vezes as leituras em grupos e cada vez mais motivadas por perguntas que facilitem a entrada dos estudantes de iniciação científica nos textos, visando confortá-los como leitores e utilizadores dos conceitos teóricos.

- O conhecimento das teorias: as leituras em grupo, sempre mediadas pelos mais experientes, devem facilitar o contato mais rápido com as teorias mais centrais do campo e dos projetos dos estudantes. Os estudantes têm dificuldades em definir o caminho de acesso à teoria central do seu trabalho e, por isso, tendem a citar autores e conceitos incompatíveis, fontes que estão em campos distintos e opostos, sem gerenciamento, ou seja, citam por citar e, por isso, acabam sobrepondo ideias e conceitos. Nesse caso, convém orientar o estudante, o quanto antes, para ler as fontes certas, ler discursos fundadores e diminuir o apego a autores, pessoas. Na prática, o papel do orientador ou supervisor continua sendo indispensável, uma vez que acompanham os passos dos estudantes de lugares privilegiados e, por isso, sabem conduzir uma questão de pesquisa aos pressupostos mais precisos e às fontes mais acessíveis.

- O exercício da escrita: a escrita da pesquisa é uma experiência alongada durante todo o período dos estudos e nunca se deve deixar para o final do curso. Ao longo dos estudos, os jovens em estágio de iniciação científica devem, mais do que conhecer normas técnicas, experimentar ou pôr em prática o jogo enunciativo implicado na escrita da pesquisa. Assim, na fase inicial, todo estudante de licenciatura de qualquer curso deve ser encorajado a participar de atividades de comunicação científica em eventos específicos. Não basta, porém, visar à quantidade das publicações, tendo em vista a exigência curricular, mas também a qualidade do que se aprende no exercício da escrita. Nas universidades, infelizmente, esse exercício, apesar da sua importância, ainda é privilégio de uma minoria, quase sempre dos estudantes contemplados com bolsas de iniciação científica. A nossa sugestão é que, se as universidades optam pela introdução da pesquisa e da escrita da pesquisa na graduação e nas licenciaturas, então, é preciso tirar o máximo de proveito desse fato para formar bons leitores e escritores da ciência, já nessa etapa. 
Por fim, essas sugestões, embora poucas, são um ponto de partida para que as Universidades, em especial nas licenciaturas de letras, linguística e educação, comecem a buscar as causas das dificuldades dos estudantes com o tratamento da informação teórica em suas escritas, mas que também o corpo docente assuma esse objeto de investigação como um laboratório de revisão das políticas de letramento e de acesso à informação. Sendo esse um novo desafio, os resultados podem trazer grandes mudanças para a formação científica e acadêmica, para as áreas de conhecimentos e, também, para o futuro da pesquisa em nível de pós-graduação.

Além dessa atenção mais fortalecida à iniciação científica, os estudos da referência ao discurso do outro ou simplesmente os estudos da citação devem incluir novos objetos. A investigação sobre o comportamento desse objeto a partir dos pressupostos do letramento social, intercultural e informacional poderá apontar o processo de inclusão dos novos estudantes universitários beneficiados pela política de expansão da educação superior, como está ocorrendo no Brasil nos últimos anos, e também investigar a trajetória de estudantes de diferentes países, em processo de inclusão nas licenciaturas portuguesas. Há também de se considerar como um objeto de investigação com bons resultados para os estudos do letramento na Universidade uma pesquisa que focalize a trajetória de estudantes, desde os primeiros contatos com a escrita de pesquisa, até os estados mais superiores, por exemplo, quando saem do mestrado e do doutoramento.

Essas possibilidades, sem dúvida, somente mostram o quanto a investigação sobre a citação ou sobre qualquer modo de referência ao discurso teórico ainda é atraente e promissor, podendo suscitar inúmeras respostas sobre a complexidade do letramento acadêmico e informacional.

\section{REFERÊNCIAS BIBLIOGRÁFICAS}

ANDRÉ, M. E. D.A. (1995). Etnografia da prática escolar. São Paulo: Papirus.

BAKHTIN, M. (2006). Marxismo e Filosofia da Linguagem. Trad. Michel Lahud e Yara Frateschi Vieira. São Paulo, $12^{a}$ Edição, Hucitec.

BARTON, D. (1994). Literacy: an introducion to the ecology of written language. Oxford: Blackwell. BARTON, D. \& HAMILTON, M. (1998). Local literacies: reading and writing in one community. London and New York, Routledge.

BOCH, F. \& GROSSMANN, F. (2002). Referir-se ao discurso do outro: alguns elementos de comparação entre especialistas e principiantes. Trad. Maria de Lourdes Meirelles Matencio. SCRIPTA, Belo Horizonte, v. 6, n. 11, p. 97-108, $2^{\circ}$ sem. 
BOCH, F. \& GROSMANN, F. (2001). De l'usage des citations dans le discours théorique: des constats aux propositions didactiques. LIDIL, Grenoble, n.24. p.91-113.

CHAROLLES, M. (1997). Introdução aos problemas da coerência dos textos: abordagem teórica e estudo das práticas pedagógicas. In: GALVES, C.; ORLANDI, E. \& OTONI, P. O texto: leitura e escrita. Campinas: Pontes.

CAVALCANTI, M. (1998). AILA 1996 e um estado da arte em microcosmo da Linguística Aplicada. In: SIGNORINI, I. \& CAVALCANTE, M. (Org.) Linguística Aplicada e transdisciplinaridade. Campinas: Mercado de Letras.

DENZIN, N. K. \& LINCOLN, Y.S. (1998). The landscape of qualitative research. London: Sage.

COMPAGNON, A. (2007). O trabalho da citação. Trad. Cleonice P. B. Mourão. Belo Horizonte: Editora da UFMG.

CRINON, M. (2001). L'usage des lectures dans l'élaboration et l'exposition des mémoires professionnels d'IUFM. LIDIL, Grenoble, n.24, p.71-49.

ERICKSON, F. (1987). Transformacion and school success: the politics and culture of educacional achievement. Antbropology Education Quarterly, vol. 18 (4) pp. 35-56, december.

ERICKSON, F. (1989). Metodos cualitativos de investigacion sobre la enseñanza. In: MERLIN, C. W. La investigacion de la ensenãnanza, II: métodos cualitativos y de observación. Barcelona: Paidos.

ERICKSON, F. (2001). Prefácio. In: COX, M. I. P. \& ASSIS-PETERSON, A. A. de A. (orgs.). Cenas de sala de aula. Campinas: Mercado de Letras.

GRAMSCI, A. (1995). Concepção dialética da bistória. 10a ed. Trad. Carlos Nelson Coutinho. Rio de Janeiro: Civilização Brasileira.

GUERNIER, M-C. (2001). Lire um texte théorico-didactique ou quelle competénce pour une lecture "professionelle" en formation d'enseignants. LIDIL, Grenoble, n.24, p. $113-135$.

GUILBERT, R. (2001). Citer e se situer: 1'apprentissage d'1 écriture avec les discours d'autrui. LIDIL, Grenoble, n.24, p.29-49.

IVANIC, R. (1998). Writing and identity: the discoursal construction of identity in academic writing. John Benjamin Publishing Company. Amsterdam/Philadelphia.

KLEIMAN, A. (Org.) (1995). Os significados do letramento: uma nova perspectiva sobre a prática social da escrita. Campinas: Mercado de Letras.

KLEIMAN, A. (1998). O estatuto disciplinar da Linguística Aplicada: o traçado de um percurso, um rumo para o debate. In: SIGNORINI, I. \& CAVALCANTE, M. (org.) Linguística Aplicada e transdisciplinaridade. Campinas: Mercado de Letras.

MARCUSCHI, Luiz. Antônio. (2001). Da fala para a escrita: atividades de retextualização. São Paulo: Cortez.

MATÊNCIO, M. L. (2003). Atividade de (re) textualização em práticas acadêmicas: um estudo sobre o gênero resumo. Scripta, no 11, p.109-122. Belo Horizonte: PUCMinas. 
SANTOS, C. B. dos. (2003). A construção do conceito de coerência textual por professores em formação. Trabalhos em Linguística Aplicada, Campinas: Unicamp, n. 41, p. 91-103.

SANTOS, C. B. dos (2006). A construção da definição de pedagogia progressista pelo professor em formação. Revista da FAEEBA: Educação e contemporaneidade, Salvador, v. 15, n. 26 , jul./dez.

SANTOS, C. B. dos (2005). Um assunto puxa o outro: a representação da coerência textual na formação do alfabetizador. Tese de Doutorado inédita. IEL/Unicamp.

SILVA, A. M. da (2008). Inclusão Digital e Literacia Informacional em Ciência da Informação. PRISMA.COM, nº 7, p.17-43.

SILVA, A. M. da. (2010). Mediação e mediadores em ciência da informação. PRISMA. COM, n ${ }^{\circ} 9$.

SPINK, M. J. (1993). O estudo empírico das representações sociais. In: SPINK, M.J. (Org.) O conbecimento no cotidiano - as representações sociais na perspectiva da Psicologia Social. São Paulo: Brasiliense.

STREET, B. (2006). Perspectivas interculturais sobre o letramento. Filol. Linguística Portuguesa. n.8.p.451-464.

UNIVERSIDADE DE AVEIRO. (2015). Citar e referenciar: estilo bibliográfico APA 6 th. AveiroPT, Serviços de Biblioteca, Informação Documental e Museologia (SBIDM/UA).

UNIVERSIDADE ESTADUAL DE CAMPINAS (2008). Guia de Normalização ABNT para Referências e Citações. Campinas (SP): Sistema de Biblioteca da Unicamp (SBU).

Recebido: 12/03/2015

Aceito: 11/03/2016 